\title{
Farklı Yapay Besin Ortamlarının Galleria mellonella (L.) (Lepidoptera: Galleriidae)'nın Gelişimine Etkisi
}

\author{
Meltem Avan* Avni Uğur \\ Ankara Üniversitesi, Ziraat Fakültesi, Bitki Koruma Bölümü, 06120 Dışkap1/Ankara \\ *Sorumlu yazar: meltem_avn@hotmail.com
}

Geliş Tarihi: 26.04.2019

Kabul Tarihi: 25.06.2019

\section{$\ddot{O} \mathbf{z}$}

Bu çalışmada Galleria mellonella (L.) Wiesner (1993), Deseo et al. (1990), Marston ve Ertle (1973), Haydak (1936), ilk kez denemeye alınan A ve B adı verilen yapay besin ortamlarında yetiştirilerek, bu besin ortamlarının larva gelişme süresi, pupa gelişme süresi, ergin yaşama süresi etkisi araştırılmıştır. Denemeler $29 \pm 2^{\circ} \mathrm{C}$ sıcaklık ve $\% 60-70$ orantılı neme sahip inkübatörde yürütülmüştür. Elde edilen sonuçlara göre çalışmada ele alınan besin ortamlarından, Deseo'nun besin ortamı ile A besin ortamı hem en iyi gelişimi sağlayan, hem de en düşük maliyetli en iyi iki besin ortamı olarak anlaşılmaktadır. Bu iki besin ortamının, G. mellonella'nın özellikle gelişimi ve canlılığı bakımından diğer ortamlara göre daha uygun olduğu görülmektedir.

Anahtar Kelimeler: Galleria mellonella, Balmumu güvesi, biyoloji, gelişim, yapay besin, etki

\section{The Effect of Different Artificial Diets on the Development of Galleria mellonella (L.) (Lepidoptera: Galleriidae)}

\section{Abstract}

Galleria mellonella (L.) has been reared using the rearing methods of Wiesner (1993), Deseo et al. (1990), Marston and Ertle (1973), Haydak (1936), A and B artificial diets and investigated the effects of these diets on the duration of larval development, pupal development and adult longevity. Experiments were carried out under the conditions of $29 \pm 2^{\circ} \mathrm{C}$ and $60-70 \%$ r.h. in controlled condition. In conclusion, Deseo et al.'s and A's diets are the best among the other diets, because these two diets are cheaper and more suitable regarding for the mass production and biological parameters of Galleria mellonella.

Keywords: Galleria mellonella, Greater wax moth, biology, development, artificial diet, effect

\section{Giriş}

Galleria mellonella (L.) peteklerde ve arı kovanlarında ve depo balmumlarında zarar yapan tüm dünyada ve ülkemizde çok yaygın bir zararlıdır. Ancak arı yetiştiricilerin arıları kontrol ve bakımı güç, zararlı böceklerin gelişmesine elverişli kovanlarda yetiştirmeleri, aynı zamanda gerekli koruyucu tedbirlerin alınmaması zararın artmasına neden olmuştur (Özer 1962). Zacher (1927) zararlının biyoloji ve yayılışını belirterek Avrupa, Kuzey Amerika, Avustralya, Yeni Zelanda, Hindistan'da zararlıya rastlandığını bildirmiş̦tir. Haydak (1936) laboratuvar böceklerinin yetiştirilmesi bal, gliserin, süt tozu, maya, buğday kepeği, buğday unundan meydana gelen besin ortamından bahsetmiştir. Roy (1949) G. mellonella'nın biyolojisi, zararları ve yayılış alanlarını araştırmıştır. Gülşahin (1955) G. mellonella'nın biyolojisi, zararları ve yayılışı üzerinde durmuştur ve larva gelişimini ortalama 30 günde, pupa gelişimini ortalama 8-9 günde tamamladığını ifade etmiş̧tir.

Beck (1960) balmumu güvesinin büyümesi ve gelişmesi hakkında bilgi vermiştir. Kullandığ 1 stok kültürlerinin yetiştirilmesi, bakımı ve yeni bir ortamdan bahsetmiştir. Bu besin ortamı ise $25 \mathrm{~g}$ bal, $22 \mathrm{~g}$ gliserin, $10 \mathrm{~g}$ su, $34 \mathrm{~g}$ tahıl, $10 \mathrm{~g}$ maya ve $5 \mathrm{~g}$ balmumundan oluşmuştur. Besinin ya da konukçunun farklı olması, böceklerin ergin oluncaya, hatta gelişmelerinin belli evresini tamamlayıncaya kadar canlı kalanların oranını değiştirebilmektedir. Farklı besin alan larvalardan meydana gelecek erginler arasında çoğunluk belirgin irilik farklılığı görülür (Kansu, 1962).

Özer (1962), G. mellonella'nın morfoloji, biyoloji ve yayılışı üzerine araştırmalar yapmıştır. Yazar G. mellonella'nın morfoloji, biyoloji, zararları ve coğrafi yayılışı hakkında bilgi vermiştir. Araştırıcı pupa devresinin ise 8-14 gün olduğunu ifade etmiştir. Marston ve Ertle (1973) G. mellonella üretimi için buğday kepeği, maya, buğday unu, mısır unu, gliserinden oluşan besin ortamından 
bahsetmiştir. Uygun (1975), besin çeşitliliğinin böceklerin gelişme süresi, ölüm, çoğalma gücü, vücut yapısı, cinsiyet ve renk üzerindeki etkilerini açıklamaktadır.

Düzgüneş ve ark. (1987) yaptıkları çalışmalarında varyans analizi Duncan testi vb. istatistiksel hesaplamalardan bahsetmişlerdir. Besinin çeşitli olması gelişme sürelerine, ergin hale geçen birey sayısına, bireyin iriliğine ve çoğalma gücüne etkide bulunmaktadır (Kansu, 1988). Deseo ve ark. (1990) G. mellonella üretimi için gliserin, buğday kepeği, su, bal ve petekten oluşan bir besin ortamından bahsetmiştir. Wiesner (1993) yaptığı çalışmasında G. mellonella üretimi için mısır unu, buğday kepeği, süt tozu, bal, gliserin, maya ve balmumundan oluşan besin ortamını bildirmiştir. Galleria mellonella larva ve pupaları bir çok parazitoid böceklerin laboratuvarda çoğaltılabilmesi için kullanılmaktadır (Wiedenmann ve ark., 1992; Büyükgüzel, 2001) ve kolay yetiştirilmesi açısından oldukça tercih edilen bir türdür. Çağlar ve ark. (2001) balmumu güvesi (G. mellonella) ile bulaşık birçok arı kolonisinin olduğunu ifade etmiştir. Nurullahoğlu ve Susurluk (2001) G. mellonella larva döneminde bal, polen ve bal arılarının ürettiği balmumu ile beslenmekte olduğunu bildirmişlerdir. Sanford (2003) arı peteklerine önemli zararlara yol açan G. mellonella'ya karş1 ciddi sorunlar yaşadıklarını ifade etmiştir. Türkiye'de yaklaşık olarak 5 milyon bal arısı kolonisinden ortalama 3.500-4.000 ton/y1l bal mumu üretilmektedir (Anonim, 2006).

$\mathrm{Bu}$ çalışmada gelişimi, ekolojik uyumu, besin tercihi nedeniyle araştırmalarda ve biyolojik kontrol ajanı olarak tercih edilen G. mellonella'nın altı değişik besin ortamında larva gelişme süresi, pupa gelişme süresi, ergin yaşama süresi belirlenmeye çalışılmıştır. Araştırma sonunda zararlı için hangi besin ortamının ya da ortamlarının daha uygun olduğu sonucuna varmak hedeflenmiştir. Denemelerde Haydak (1936), Marston ve Ertle (1973), Deseo et al. (1990) ve Wiesner (1993) tarafından önerilen besin ortamları ile ilk kez denemeye alınan A ve B adı verilen iki besin ortamı daha kullanılmıştır. Çalışma Ankara Üniversitesi Ziraat Fakültesi Bitki Koruma Bölümü'nde yürütülmüştür.

\section{Materyal ve Yöntem \\ Materyal}

Çalışmada yer alan Galleria mellonella'nın yumurtaları Ankara Üniversitesi Ziraat Fakültesi Bitki Koruma Bölümü'nün stok kültüründen alınmıştır.Yumurtalar çok küçüktür, renk olarak kremsi pembe ve beyazımtrak olup $0,45 \mathrm{~mm}$ uzunluğunda ve $0,4 \mathrm{~mm}$ çapındadır. Ağırlığ $0.028 \mathrm{mg}$ kadardır. Yumurtadan yeni çıkan larva krem renkli olup hareket yeteneği çoktur. Ergin kelebek açık kahverengigri renktedir (Özer 1962).

$\mathrm{Bu}$ araştırmada G. mellonella'nın yetiştirilmesinde Wiesner (1993)'in besin ortamı kullanılmıştır. Denemelerde ise besin ortamı olarak Wiesner (1993)'in, Deseo et al. (1990)'nun, Marston ve Ertle (1973)'un, Haydak (1936)'ın ve ilk kez denemeye alınan A ve B harfleriyle ifade edilen iki besin ortamını daha kullanılmıştır. Denemede kullanılan tüm besin ortamları ve içerikleri aşağıdaki gibidir:

Haydak (1936) tarafindan bildirilen besin ortamı: $500 \mathrm{~g}$ bal, $500 \mathrm{~g}$ gliserin, $445 \mathrm{~g}$ süt tozu, 222 g kuru ekmek mayası, $445 \mathrm{~g}$ buğday kepeği, $890 \mathrm{~g}$ buğday unu.

Marston ve Ertle (1973) tarafından bildirilen besin ortamı: $260 \mathrm{~g}$ buğday kepeği, $65 \mathrm{~g}$ maya, $162 \mathrm{~g}$ buğday unu, $162 \mathrm{~g}$ misır unu, $193 \mathrm{~g}$ gliserin.

Deseo et al. (1990) tarafından bildirilen besin ortamı: $378 \mathrm{~g}$ gliserin, $800 \mathrm{~g}$ buğday kepeği, 148 $\mathrm{g}$ su, $288 \mathrm{~g}$ süzme bal, $200 \mathrm{~g}$ balmumu.

Wiesner (1993) tarafından bildirilen besin ortamı: \%22 misır unu, \%22 buğday kepeği,\%11 süt tozu, $\% 11$ bal, $\% 11$ gliserin, $\% 5,5$ maya, $\% 17,5$ balmumu.

A : $125 \mathrm{~g}$ misır unu, $125 \mathrm{~g}$ buğday kepeği, $62 \mathrm{~g}$ süt tozu, $70 \mathrm{~g}$ pekmez, $62 \mathrm{~g}$ gliserin, $30 \mathrm{~g}$ maya.

B : $125 \mathrm{~g}$ misır unu, $125 \mathrm{~g}$ buğday kepeği, $62 \mathrm{~g}$ süt tozu, $200 \mathrm{~g}$ balmumu, $62 \mathrm{~g}$ gliserin, $30 \mathrm{~g}$ maya.

\section{Yöntem}

Galleria mellonella'nın yetiştirilmesinde mısır unu, kepek, süt tozu, bal, gliserin, maya, petek (4:4:2:2:2:1:3)'den oluşan besin ortamı kullanılmıştır. Bunun için balmumu güvesi yumurtaları önce 1/3'ü besinle doldurulmuş 1 litrelik cam kavanozlara alınıp ve ağzı sineklik teli ve metal kelepçe ile kapatılmıştır ve kavanozlardaki larvalar 8 günlük olduktan sonra yine 1/3'ü besinle dolu 330 ml'lik 10 
ayrı cam kavanozun içerisine 20'şer tane 8 günlük larvalar pensle alınıp konulmuştur ve bu kavanozlarında ağızları sineklik teli ve metal kelepçe ile kapatılmıştır. Kullanılan inkübatörün sicaklığ $29 \pm 2^{\circ} \mathrm{C}$, ortalama orantılı nemi $\% 60-70$ 'e ve karanlıkta olacak şekilde ayarlanmıştır.

Çalışmada farklı yapay besin ortamlarında G. mellonella'nın larva ve pupalarının gelişme süresi, ergin ömrü araştırılmıştır.

Denemeler her gün kontrol edilerek besini azalanlara besin ilave edilmiştir. Pupa olanlar alınarak pupa oluş tarihleriyle beraber ölenler ve gelişimini tamamlayamayan larvalar kaydedilmiştir. İçerisinde besin bulunan kavanozlar her gün kontrol edilerek pupa olanlar alınmıştır. Tüm larvalar pupa oluncaya kadar bu işleme devam edilmiştir. Pupalarda cinsiyet ayrımı abdomenin son segmentlerine bakılarak yapılmıştır. Dişi pupada cinsiyet ayrımı, 8. abdomen segmentinin ventralinde ve segmentin hemen başlangıcında boyuna uzanan bir çizginin olduğu yerde 7. ile 8. segmenti birleştiren çizginin 8 . segmente doğru bir çıkıntı meydana getirmesi ile ayrılır. Erkek pupa ise 7 . ve 8 . segmenti birleştiren çizgi düzgün oluşu ve genital açıklı̆̆ın 9. segmentte bulunuşu ve bir çift kabartı şeklinde oluşuna göre ayrılmaktadır.

Cinsiyetleri ayrılmış pupaların içinde bulunduğu kavanozlar her gün kontrol edilerek ergin oluş tarihleriyle beraber ölenler ve gelişimini tamamlayamayan pupalar da kaydedilmiştir. Çıkan erginler aynı etiket numaralı kavanozlara tekrar alınmış ve erginlerin yaşama süresinin takibi için bekletilmiştir.

Tüm besin ortamları ve cam malzemeler kullanımdan önce $60^{\circ} \mathrm{C}$ sıcaklıkta 3 saat tutularak sterilize edilmiştir (Güçlü 1976). Diğer araçlar \%l'lik sodyum hipoklorit ile dezenfekte edilmiştir.

Çizelge 1. Çalışmada ele alınan her bir besin ortamı için denemelerde kullanılan G. mellonella'ya ait birey sayıları

\begin{tabular}{lcccccc}
\hline \multicolumn{1}{c}{ Denemeler } & $\begin{array}{c}\text { Wiesner } \\
(1993)\end{array}$ & $\begin{array}{c}\text { Deseo et al. } \\
(1990)\end{array}$ & $\begin{array}{c}\text { Marston ve } \\
\text { Ertle } \\
(1973)\end{array}$ & $\begin{array}{c}\text { Haydak } \\
(1936)\end{array}$ & A & B \\
\hline $\begin{array}{l}\text { Larva } \\
\text { gelişme } \\
\text { süresi }\end{array}$ & 200 & 200 & 200 & 200 & 200 & 200 \\
\hline $\begin{array}{l}\text { Pupa gelişme } \\
\text { süresi }\end{array}$ & 173 & 149 & 170 & 190 & 180 & 180 \\
\hline $\begin{array}{l}\text { Ergin yaşama } \\
\text { süresi }\end{array}$ & 146 & 120 & 162 & 181 & 167 & 171 \\
\hline
\end{tabular}

Üzerinde durulan özellikler bakımından besin ortamları arasında ve cinsiyetler arasında fark olup olmadığını belirlemek amacıyla faktöriyel varyans analizi yapılmıştır. Larva ve pupa gelişme süresi, ergin yaşama süresi bakımından besin ortamları ve cinsiyetlerin karşılaştııılması amacıyla tek faktörlü varyans analiz tekniği uygulanmış, farklı besinlerin etkilerinin belirlenmesinde çoklu karşılaştırma yöntemlerinden Duncan testi kullanılmıştır. Hesaplamalarda "Minitab" ve "İstatistica" istatistik paket programları kullanılmıştır.

\section{Bulgular ve Tartışma}

Farklı yapay besin ortamlarının Galleria mellonella'nın larva gelişime süresine etkisi

Çalışmada G. mellonella altı farklı besin ortamında yetiştirilmiş ve larva gelişme süresi bakımından farklılık olup olmadığ 1 araştırılmıştır. Yapılan istatistiki kontroller sonucunda farklı besin ortamlarında yetiştirilen G. mellonella larvalarının farklı gelişme sürelerine sahip olduğu görülmüştür $(\mathrm{P}<0.01)$. Ancak cinsiyetlerin larva gelişme süreleri arasındaki farklılık tesadüften ileri gelmektedir (Çizelge 2, Şekil 1). Larva gelişme süresinin en kısa olduğu besin ortamı Deseo et al. (1990)'nun besin ortamıdır. Bu besin ortamında yetiştirilen larvaların gelişme süresi ortalama 23,262 $\pm 0,165$ gündür. En uzun larva gelişme süreleri ise Marston ve Ertle (1973)'in ve Haydak (1936)'n besin ortamlarında gözlemlenmiştir. Anılan besin ortamlarında yetiştirilen larvaların gelişme süresi sırasıyla ortalama $27,529 \pm 0,208$ ve $28,328 \pm 0,166$ gündür. 
Çizelge 2. Galleria mellonella dişi ve erkek larvalarının farklı yapay besin ortamlarındaki gelişme süresi

\begin{tabular}{|c|c|c|c|c|c|c|c|}
\hline \multirow{3}{*}{$\begin{array}{c}\text { Besin } \\
\text { Ortamlar1 }\end{array}$} & \multicolumn{7}{|c|}{ Larva Gelişme Süreleri (gün) } \\
\hline & \multicolumn{3}{|c|}{ Dişi } & \multicolumn{3}{|c|}{ Erkek } & \multirow{2}{*}{$\begin{array}{l}\text { Genel } \\
\text { Ort. }\end{array}$} \\
\hline & $\begin{array}{l}\text { En } \\
\text { az }\end{array}$ & $\begin{array}{l}\text { En } \\
\text { çok }\end{array}$ & Ort. & $\begin{array}{l}\text { En } \\
\text { az }\end{array}$ & $\begin{array}{l}\text { En } \\
\text { çok }\end{array}$ & Ort. & \\
\hline $\begin{array}{l}\text { Wiesner } \\
\text { (1993) }\end{array}$ & 14 & 30 & $27,212 \pm 0,329$ & 14 & 30 & $26,912 \pm 0,346$ & $27,069 \pm 0,204 \mathrm{~b}$ \\
\hline $\begin{array}{l}\text { Deseo et al. } \\
(1990)\end{array}$ & 15 & 27 & $23,091 \pm 0,336$ & 14 & 26 & $23,501 \pm 0,398$ & $23,262 \pm 0,165 \mathrm{c}$ \\
\hline $\begin{array}{l}\text { Marston ve } \\
\text { Ertle (1973) }\end{array}$ & 15 & 32 & $27,523 \pm 0,336$ & 13 & 35 & $27,542 \pm 0,344$ & $27,529 \pm 0,208 \mathrm{ab}$ \\
\hline $\begin{array}{l}\text { Haydak } \\
\text { (1936) }\end{array}$ & 14 & 32 & $28,540 \pm 0,309$ & 15 & 30 & $28,071 \pm 0,338$ & $28,328 \pm 0,166 \mathrm{a}$ \\
\hline A & 16 & 31 & $26,671 \pm 0,329$ & 19 & 32 & $27,350 \pm 0,338$ & $27,011 \pm 0,240 \mathrm{~b}$ \\
\hline $\mathrm{B}$ & 14 & 30 & $26,791 \pm 0,327$ & 9 & 31 & $27,011 \pm 0,336$ & $26,899 \pm 0,245 \mathrm{~b}$ \\
\hline
\end{tabular}

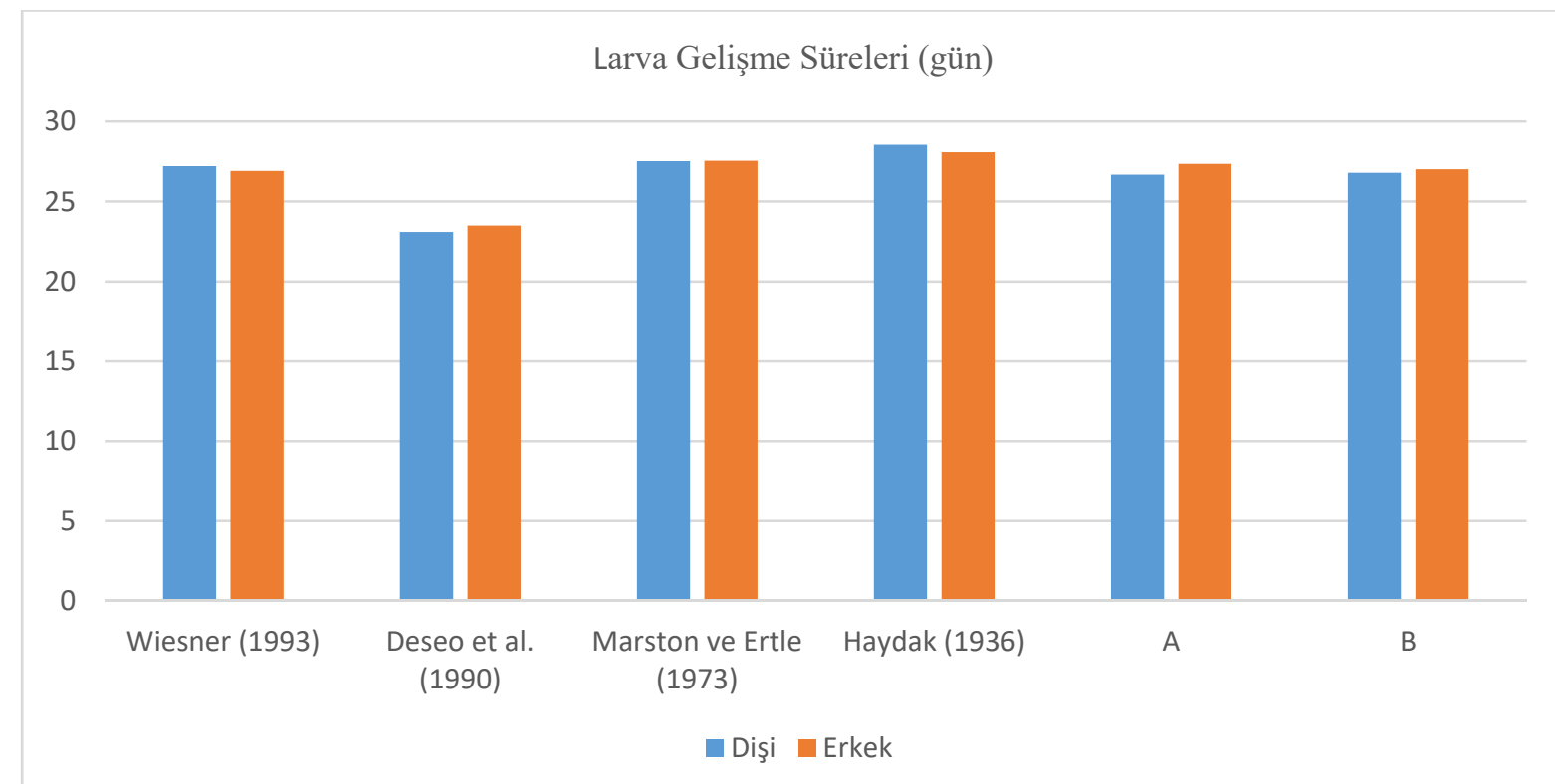

Şekil 1. Galleria mellonella dişi ve erkek larvalarının farklı yapay besin ortamlarındaki gelişme süresi

Farklı yapay besin ortamlarının Galleria mellonella'nın pupa gelişime süresine etkisi

Farklı besin ortamlarında Galleria mellonella pupalarından elde edilen sonuçlara göre yapılan istatistiki kontroller sonucunda farklı besin ortamlarının, pupa gelişme süresine etkide bulunduğu saptanmıştır $(\mathrm{P}<0,01)$. Ancak cinsiyetler arasındaki pupa gelişme sürelerindeki farklılı̆̆ın ise tesadüften ileri geldiği gözlemlenmiştir (Çizelge 4.2, Şekil 4.2). Pupa gelişiminin en kısa sürede tamamlandığı besin ortamları Wiesner (1993), Haydak (1936) ve A besin ortamlarıdır. Anılan besin ortamlarında yetiştirilen larvalardan elde edilen pupaların gelişme süreleri sırasıyla ortalama $8,744 \pm 0,171,8,931 \pm 0,143$ ve $8,809 \pm 0,160$ günde tamamlanmıştır. Pupa gelişiminin en uzun sürede

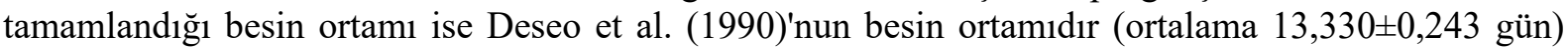
(Çizelge 3, Şekil 2). 
ÇOMÜ Zir. Fak. Derg. (COMU J. Agric. Fac.)

2019: 7 (1): 39-46

ISSN: 2147-8384 / e-ISSN: 2564-6826

doi: 10.33202/comuagri.558398

Çizelge 3. Galleria mellonella'nın dişi ve erkek pupalarının farklı yapay besin ortamlarındaki gelişme süreleri

\begin{tabular}{|c|c|c|c|c|c|c|c|}
\hline \multirow{3}{*}{$\begin{array}{c}\text { Besin } \\
\text { Ortamları }\end{array}$} & \multicolumn{7}{|c|}{ Pupa Gelişme Süreleri (gün) } \\
\hline & \multicolumn{3}{|c|}{ Dişi } & \multicolumn{3}{|c|}{ Erkek } & \multirow{2}{*}{$\frac{\text { Genel }}{\text { Ort. }}$} \\
\hline & $\begin{array}{l}\text { En } \\
\text { az }\end{array}$ & $\begin{array}{l}\text { En } \\
\text { çok }\end{array}$ & Ort. & $\begin{array}{l}\text { En } \\
\text { az }\end{array}$ & $\begin{array}{l}\text { En } \\
\text { çok }\end{array}$ & Ort. & \\
\hline $\begin{array}{l}\text { Wiesner } \\
\text { (1993) }\end{array}$ & 5 & 14 & $8,700 \pm 0,0024$ & 4 & 14 & $8,793 \pm 0,027$ & $8,744 \pm 0,171 \mathrm{bc}$ \\
\hline $\begin{array}{l}\text { Deseo et al. } \\
(1990)\end{array}$ & 8 & 18 & $13,241 \pm 0,023$ & 9 & 20 & $13,419 \pm 0,035$ & $13,315 \pm 0,243 \mathrm{a}$ \\
\hline $\begin{array}{l}\text { Marston ve } \\
\text { Ertle (1973) }\end{array}$ & 8 & 11 & $9,425 \pm 0,025$ & 5 & 15 & $9,317 \pm 0,027$ & $9,373 \pm 0,161 \mathrm{~b}$ \\
\hline Haydak (1936) & 6 & 13 & $9,165 \pm 0,021$ & 5 & 13 & $8,651 \pm 0,025$ & $8,931 \pm 0,143 \mathrm{bc}$ \\
\hline A & 4 & 13 & $8,451 \pm 0,024$ & 5 & 14 & $9,128 \pm 0,026$ & $8,809 \pm 0,160 \mathrm{bc}$ \\
\hline B & 8 & 13 & $8,685 \pm 0,024$ & 3 & 14 & $8,540 \pm 0,025$ & $8,615 \pm 0,160 \mathrm{c}$ \\
\hline
\end{tabular}

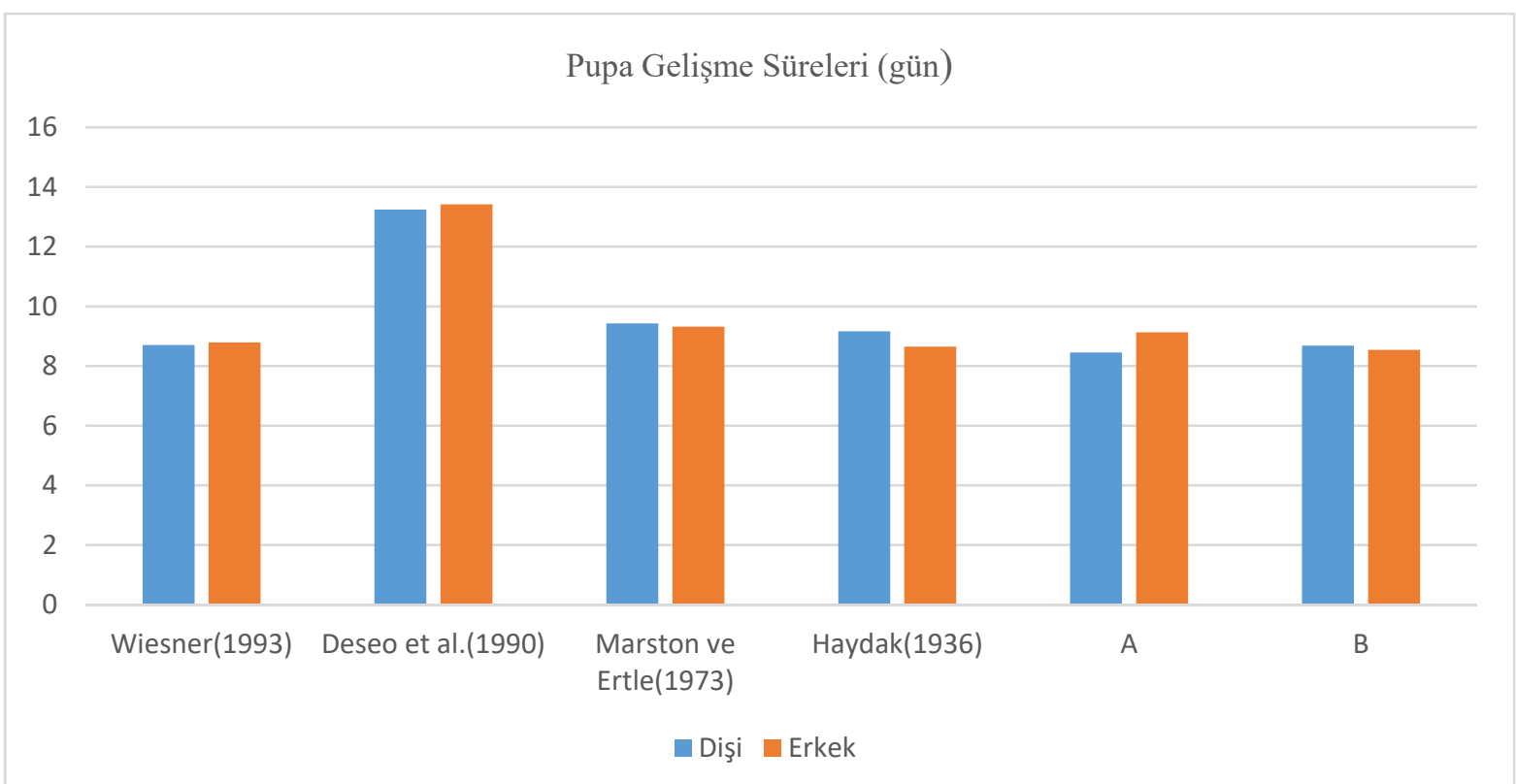

Şekil 2. Galleria mellonella dişi ve erkek pupalarının farklı yapay besin ortamlarındaki gelişme süreleri

\section{Farklı yapay besin ortamlarının Galleria mellonella'nın ergin yaşama süresine etkisi}

Farklı besin ortamlarında yetiştirilen G. mellonella larvalarından elde edilen erginlerin yaşama süreleri ile ilgili yapılan istatistiki analizler sonucunda besin ortamlarının ergin yaşama süresine etkisi önemli bulunmuştur $(\mathrm{P}<0,01)$. Ancak cinsiyetler arasındaki ergin yaşama sürelerindeki farklılık tesadüften ileri gelmektedir (Çizelge 4, Şekil 3). Ergin yaşama süresinin en kısa zamanda

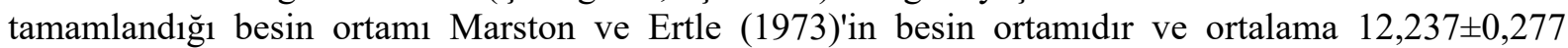
günde tamamlanmıştır. En uzun ergin yaşama süresi ise diğer besin ortamlarında kaydedilmiştir ve bu diğer besin ortamları arasındaki farklılık istatistiki olarak önemli değildir (Çizelge 4, Şekil 3). 
ÇOMÜ Zir. Fak. Derg. (COMU J. Agric. Fac.)

2019: 7 (1): 39-46

ISSN: $2147-8384$ / e-ISSN: 2564-6826

doi: 10.33202/comuagri.558398

Çizelge 4. Galleria mellonella'nın dişi ve erkek erginlerinin farklı yapay besin ortamlarındaki yaşama süreleri

\begin{tabular}{|c|c|c|c|c|c|c|c|}
\hline \multirow{3}{*}{$\begin{array}{c}\text { Besin } \\
\text { Ortamlar1 }\end{array}$} & \multicolumn{7}{|c|}{ Ergin Yaşama Süreleri (gün) } \\
\hline & \multicolumn{3}{|c|}{ Dişi } & \multicolumn{3}{|c|}{ Erkek } & \multirow{2}{*}{$\frac{\text { Genel }}{\text { Ort. }}$} \\
\hline & En az & $\begin{array}{l}\text { En } \\
\text { çok }\end{array}$ & Ort. & $\begin{array}{l}\text { En } \\
\text { az }\end{array}$ & $\begin{array}{l}\text { En } \\
\text { çok }\end{array}$ & Ort. & \\
\hline Wiesner (1993) & 7 & 23 & $14,761 \pm 0,076$ & 5 & 24 & $14,642 \pm 0,086$ & $14,701 \pm 0,333 \mathrm{a}$ \\
\hline $\begin{array}{l}\text { Deseo et al. } \\
(1990)\end{array}$ & 8 & 23 & $15,212 \pm 0,084$ & 10 & 23 & $16,200 \pm 0,104$ & $15,629 \pm 0,305 \mathrm{a}$ \\
\hline $\begin{array}{l}\text { Marston ve } \\
\text { Ertle (1973) }\end{array}$ & 7 & 22 & $12,320 \pm 0,069$ & 6 & 19 & $12,153 \pm 0,076$ & $12,237 \pm 0,277 \mathrm{~b}$ \\
\hline Haydak (1936) & 7 & 22 & $14,721 \pm 0,058$ & 8 & 21 & $14,312 \pm 0,070$ & $14,530 \pm 0,238 \mathrm{a}$ \\
\hline $\mathrm{A}$ & 5 & 24 & $14,910 \pm 0,068$ & 9 & 24 & $16,052 \pm 0,072$ & $15,446 \pm 0,306 \mathrm{a}$ \\
\hline $\mathrm{B}$ & 7 & 22 & $14,242 \pm 0,065$ & 9 & 24 & $16,043 \pm 0,071$ & $15,105 \pm 0,346 \mathrm{a}$ \\
\hline
\end{tabular}

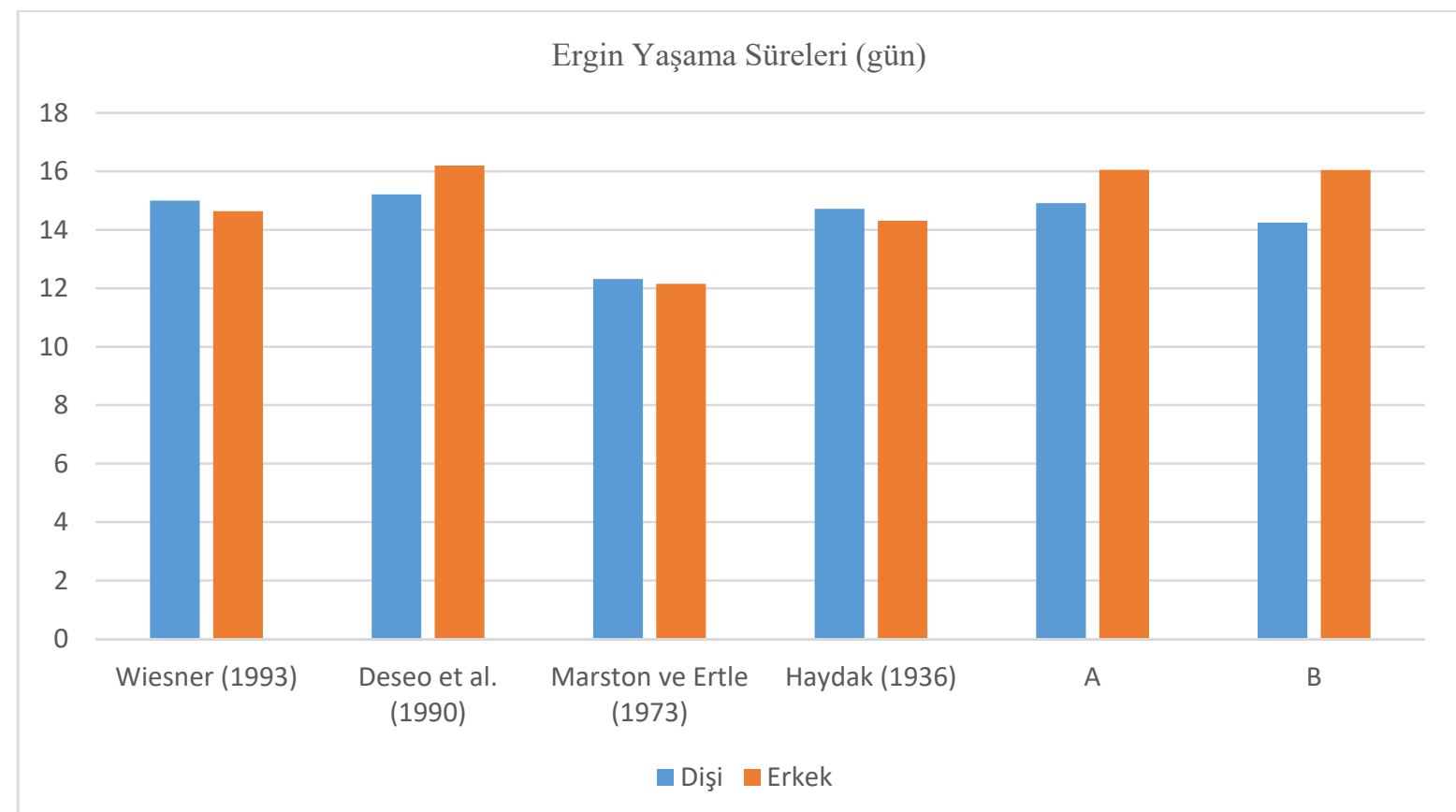

Şekil 3. Galleria mellonella dişi ve erkek erginlerinin farklı yapay besin ortamlarındaki yaşama süreleri

Galleria mellonella yetiştirilmesinde kullanılan altı besin ortamının 100 g'larının besinden kaynaklanan maliyetleri hesaplandığında en ekonomik maliyetli besinden, en fazla maliyetli besin ortamına doğru;

Marston ve Ertle (1973)'in besin ortam $:$ 6,650 TL/100 g

Deseo et al. (1990)'1n besin ortam : 5,190 TL/100 g

A besin ortam1 : 5,040 TL/100 g

B besin ortam $1: 5,450 \mathrm{TL} / 100 \mathrm{~g}$

Wiesner (1993)'in besin ortam $1: 5,310 \mathrm{TL} / 100 \mathrm{~g}$

Haydak (1936)'ın besin ortamı : 3,350 TL/100 g olarak hesaplanmıştır.

Özellikle kitle üretim çalışmalarında amaç, kitle üretimi yapılan böceğin en düşük fiyatla, en iyi gelişimi sağlayacak besin ortamını kullanmaktır. Yapılan çalışmalar sonucunda en kısa larva gelişme süresi Deseo et al. (1990) ve A besin ortamından, en kısa pupa gelişme süresi ve pupa 
gelişimini tamamlama oranı ise yine A besin ortamında olduğu gözlemlenmiştir. Ergin olma oranı ise hem Deseo et al. (1990), hem de A besin ortamında yüksek olarak saptanmıştır.

Bu durumda çalışmada ele alınan besin ortamlarından, Deseo et al.(1990)'ın besin ortamı ile A besin ortamı bu şartlara uyan en iyi iki besin ortamı olarak anlaşılmaktadır. Bu iki besin ortamının, $G$. mellonella'nın özellikle gelişimi ve canlılığı bakımından diğer ortamlara göre daha uygun olduğu görülmektedir.

\section{Sonuçlar ve Öneriler}

Galleria mellonella altı farklı besin ortamında yetiştirilerek besin çeşitliliğinin böceklerin gelişimi üzerine etkileri araştırılmıştır. Besin ortamı olarak Wiesner (1993), Deseo et al. (1990), Marston ve Ertle (1973), Haydak (1936) ile yeni denenen A ve B harfleriyle adlandırılan iki besin ortamı daha kullanılmıştır. Farklı besin ortamlarında yetiştirilen balmumu güvesinde larva gelişme süresi, pupa gelişme süresi, ergin yaşama süresi, bakımından fark olup olmadığ1 araştırılmıştır.

Roy ve Sturtevant $(1962)$, yumurta kuluçka müddetinin $24-27^{\circ} \mathrm{C}\left(75-80^{\circ} \mathrm{F}\right)$ 1sıda 5-8 gün, daha düşük $10-15^{\circ} \mathrm{C}\left(50-60^{\circ} \mathrm{F}\right)$ 1sıda ise 35 gün devam ettiğini bildirmektedir.

Gülşahin (1955)'e göre çevre $1 \mathrm{~s} 1 s 130^{\circ} \mathrm{C}^{\prime}$ den aşağı olursa larvanın tam gelişmesini 20-45 günde veya ortalama 30 günde tamamladığını, pupa döneminin ise 1s1 ve rutubete bağlı olarak 8-9 gün devam ettiğini ifade etmiştir.

Yapılan laboratuvar denemeleri sonucunda larva döneminin en kısa olduğu besin ortamı Deseo et al. (1990)'a ait besin ortamıdır (ortalama 23,262 $\pm 0,192$ gün). Daha sonra ise, Wiesner (1993), Marston ve Ertle (1973), A ve B besin ortamları gelmektedir. En uzun larva gelişme süresi ise Marston ve Ertle (1973) ve Haydak (1936)'n besin ortamında gözlemlenmektedir (ortalama 27,529 $\pm 0,304$ gün, $28,328 \pm 0,171$ gün).

Pupa gelişme süresinde ise cinsiyetler arasındaki farkl1lık tesadüften ileri gelmiştir. Pupa gelişme süresinin en kısa sürede tamamlandığı besin ortamları Wiesner (1993), Haydak (1936) ve A besin ortamlarıdır (ortalama 8,744 $\pm 0,172$ gün, 8,893 $\pm 0,137$ gün, 8,809 $\pm 0,161$ gün). En uzun pupa gelişme süresi ise Deseo et al. (1990)'a ait besin ortamında gözlemlenmiştir (ortalama 13,315 $\pm 0,244$ ).

Gülşahin (1955), pupa devresinin 1sı ve rutubete bağlı olarak 8-9 gün devam ettiğini bildirirken Özer (1962) ise 8-14 gün sürdügünü, Roy (1949) ve Sturtevant (1949) pupa gelişme süresinin 1sıya tabi olarak 8-62 gün sürdügünü ifade etmişlerdir. Bu bilgiler bizim elde ettiğimiz sonuçları destekleyici yöndedir.

Ergin yaşama süresi bakımından yine cinsiyetler arasındaki farklılık tesadüften ileri gelmiştir.

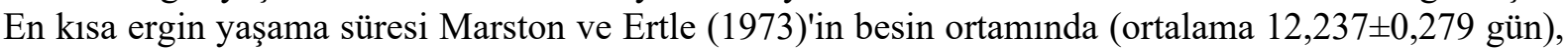
en uzun ise diğer besin ortamlarında gözlemlenmiştir ve bu diğer besin ortamları arasında da önemli farklılıklara rastlanmamıştır. Özer (1962), çiftleşen dişilerin 6-14 gün, erkek erginlerin ise 8-22 gün yaşadıklarını, çiftleşmemiş dişi ve erkek erginlerin daha fazla yaşadıklarını bildirmiştir. Whitcomb (1936) ise erginlerin 3 hafta kadar yaşadığını ifade etmiş̧tir. Gülşahin (1955)'e göre erkek erginlerin 26 gün, dişilerin 12-20 gün yaşadıklarını ifade etmiştir.

$\mathrm{Bu}$ çalışmada besin ortamı olarak dört tanesi daha önceden araştırıcıların kullandığı besin ortamlarından seçilirken, iki tanesi ise yeni oluşturulmuş besin ortamlarından kullanılmıştır. Biyolojik mücadele ajanı olarak kullanılabilmesi sebebiyle kitle üretimi önemli olan G. mellonella'nın denemelerde ele alınan besin ortamlarından Deseo et al. (1990)'ın kullandığ 1 besin ortamı ile A besin ortamının zararlının gelişimi yanında, besinden kaynaklanan maliyetleri de göz önüne alındığında, kitle üretiminde kullanılabilecek en uygun besin ortamları olduğu anlaşılmıştır.

Not: Bu çalışma Meltem AVAN'ın yüksek lisans tezinin bir kısmından hazırlanmıştır.

\section{Kaynaklar}

Anonim, 2006. DİE, Tarım İstatistikleri Özeti. DİE, Başbakanlık, Ankara

Beck, D. Stanley., 1960. Growth and development ofthe greater wax moth. Wisconsin Academy of Sciences, Arts and Letters. Vol 49: 137-149.

Büyükgüzel, K., 2001. Positive effects of some gyrase inhibitors on survival and development of Pimpla turionellae L. (Hymenoptera: Ichneumonidae) larvae reared on an artificial diet, Journal of Economic Entomology, 94, 21-26. 
Çağlar, Y., Tutkun E., Tutar, A., Yılmaz B., 2001. Balmumu Güvesi Mücadelesinde Kullanılan Kükürtdioksitin (SO2) Farklı Dozlarının Etkisi Üzerine Araştırmalar. Türkiye 3. Arıcılık Kongresi Adana.

Deseo, K.V., Ruggeri, L., Lazzari, G., 1990. Mass- production and quality control of entomopathogenic nematodes in Galleria mellonella (L.) larva. Proceeding ofthe fifth. Int. Colloquim on invertebrate pathology and microbial control, Adelia, Avustralia, August 1990, p. 250.

Düzgüneş, O., Kesici, T., Kavuncu, O., Gürbüz, F., 1987. Araştırma ve Deneme Metotları. A.Ü. Ziraat Fakültesi Yayınlar1: 1021,Ders Kitabı 295, s. 1381, Ankara.

Güçlü, Ş., 1976.Un güvesinin (Anagastra küehniella (Zeller) : Lepidoptera-Pyralidae) laboratuvar koşullarında biyo-ekolojisi, gamına radyasyonunun gelişme dönemlerine etkileri üzerinde araştırmalar. Doktora tezi, s: 1-222, Ankara.

Gülşahin, H., 1955. Balarısı hastalıkları ve zararlıları. T.C. Ziraat Vekaleti, Nesriyat ve Haberler Md. Teknik Enformasyon Servisi, Say1: 721,Gürsoy Basımevi, Ankara.

Haydak, M.H., 1936. A food for rearing laboratory insects. J. Econ. Ent. 29, 1026.

Kansu, A., 1962. Besin çeşidinin tırtılların gelişmesine etkileri ve bu konuda Lymantria dispar L. (kırtırtılı) üzerinde bir araştırma. Ankara Üniversitesi Ziraat Fakültesi Yıllığı Sayı 2'den ayrı basım:116-138, Ankara.

Kansu, A., 1988. Böcek Çevrebilimi (Böcek ökolojisi) A.Ü. Ziraat Fakültesi Yayınları: 1045, Ders kitabı: 302 , s.1-274, Ankara.

Marston, N., Ertle, L.R., 1973.Host influence on the bionomics of "Trichogramma minitum".Ann. Ent. Soc. Amer. 66: 1155-1162.

Nurullahoglu, U.Z., Susurluk A.İ., 2001. Fecundity of Turkish and German strains of Galleria mellonella (L.)(Lepidoptera: Pyralidae) reared on two different diets. S.U. Fen Edebiyat Fakültesi Fen Dergisi, 18: 39-44

Özer, M., 1962. Arı kovanlarında önemli zarar yapan balmumu güvesi Galleri mellonella L.'nın morfoloji, biyoloji ve yayılışı üzerine araştırmalar. Tarım Bakanlığı Zir. Müc. Ve Zir. Kar. Gn. Md. 'lüğü Bitki Koruma Bült., 2(12), 26- 35.

Roy, A.G., 1949. The Hive and The Honey Bee, Publ. ofthe American Bee Journal, Printed in the U.S.A by RR Donnelly- Sons Company, Chicago, and Grawfordsville, İndiana. Pp. 621.

Sanford, M.T., 2003. Controlling Wax moth, one of a series of the Entomology and Nematology Department, Florida Cooperative Extension Service, Institute of Food and Agricultural Sciences, University of Florida. EDIS Web Site at http://edis.ifas.ufl.edu.

Uygun, N., 1975. Besinin böcekler üzerindeki etkileri. Çukurova Üniversitesi Ziraat Fakültesi Yıllığı ayrı baskı say1 2: 99-115, Adana.

Whitcomb, W.JR., 1936. The wax moth and is control, U.S.D.A. Circ. 386.

Wiedenmann, R.N., Smith, J.W. ve Darnell, P.O.,1992. Laboratory rearing and biology of the parasite Cotesia flavipes (Hymenoptera: Braconidae) using Diatraea saccharalis (Lepidoptera:Pyralidae) as a host, Environmental Entomology, 21, 1160- 1167.

Wiesner, J., 1993. Neoaplectana carpocapsae, n.sp. (Anguillulata; Steinemematinae). Novy cizopasnik housenek obalece japlecne'ho.Carpocapsa pomonella L. Vestnik eskoslovenske spolecnosti 1 9: 44- 51.

Zacher, F., 1927. Die vorrants; Speicher- und Material- Schadline und ihreBekampfung. Verlagsbuch handlung, Paul Parey, Berlin. pp. 366. 